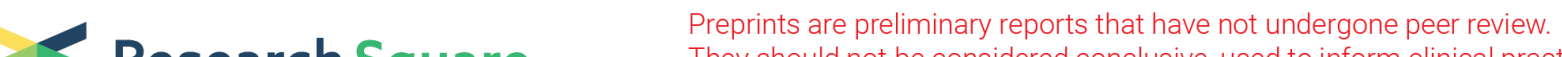 $\begin{array}{ll}\text { Research Square } & \text { They should not be considered conclusive, used to inform clinical practice, } \\ \text { or referenced by the media as validated information. }\end{array}$
}

\section{Exposure to 2,4-dichlorophenol, 2,4,6-trichlorophenol, pentachlorophenol and risk of thyroid cancer: a case- control study in China}

\author{
Wan-Jun Yang \\ Anhui Medical University \\ Hua-Bing Wu \\ Anhui Medical University
}

Chi Zhang

Anhui Medical University

Qi Zhong

Anhui Medical University

Ming-Jun Hu

Anhui Medical University

Jia-Liu He

Anhui Medical University

Guo-Ao Li

Anhui Medical University

Zhen-Yu Zhu

Anhui Medical University

Jin-Liang Zhu

Anhui Medical University

Huan-Huan Zhao

Anhui Medical University

Han-Shuang Zhang

Anhui Medical University

Fen Huang ( $\nabla$ fenh@ahmu.edu.cn )

Anhui Medical University

\section{Research Article}

Keywords: chlorophenols, thyroid cancer, environmental exposure, endocrine disrupting effect, urine

Posted Date: February 24th, 2021

DOI: https://doi.org/10.21203/rs.3.rs-203095/v1 
License: (a) (i) This work is licensed under a Creative Commons Attribution 4.0 International License. Read Full License 


\section{Abstract}

Background: Thyroid cancer (TC) has inflicted huge threats to the health of mankind. Chlorophenols (CPs) were persistent organic pollutant and can lead to adverse effects in human health, especially in thyroid. However, epidemiological studies have revealed a rare and inconsistent relationship between internal exposure to CPs and TC risk. This study was designed to examine the association between urinary CPs and risk of TC in Chinese population.

Methods: From June 2017 to September 2019, a total of 297 histologically confirmed TC cases were recruited. Age and gender matched controls were enrolled at the same time. Gas chromatography-mass spectrometry (GC-MS) was used to determine the levels of three CPs in urine. Conditional logistic regression models were adopted to assess the potential association. Restricted cubic spline function was used to explore the non-liner association.

Results: After adjusting for confounding factors, multivariate analysis showed that, compared with the first quartile, the fourth quartile concentrations of 2,4-dichlorophenol (2,4-DCP), 2,4,6-trichlorophenol (2,4,6-TCP) and pentachlorophenol(PCP) were associated with TC risk [odds ratio $(\mathrm{OR})_{2,4-\mathrm{DCP}}=2.28,95 \%$ confidence interval (Cl): 1.24-4.18; $\mathrm{OR}_{2,4,6-\mathrm{TCP}}=3.09,95 \% \mathrm{Cl}: 1.66-5.77 ; \mathrm{OR}_{\mathrm{PCP}}=3.30,95 \% \mathrm{Cl}: 1.71-6.36$, respectively]. When CPs were included in the multivariate model and restricted cubic spline function as continuous variables, presenting significant dose-response relationships. Meanwhile, whether in the TC group with tumor diameter > $1 \mathrm{~cm}$ or metastatic TC, the changes of 2,4,6 TCP and PCP concentrations were positively correlated with the risk of TC.

Conclusions: Our study suggests that higher concentrations of urinary CPs are associated with increased TC risks. Moreover, 2,4,6-TCP and PCP have certain effects on the invasiveness of thyroid cancer. Targeted public health policies should be formulated to reduce the CPs pollution. These findings need further in-depth studies to confirm and relevant mechanism also needed to be clarified.

\section{Introduction}

Thyroid cancer, one of the most common endocrine-related tumors originating from follicular or para-follicular cells, constitutes a serious burden of disease worldwide due to its rapidly growing incidence (Kato and Niebuhr, 2018). In American, the average annual percent change from 2005 through 2014 is $3.9 \%$ in both men and women (Siegel et al. 2018). According to National Cancer Center of China, the incidence rate of thyroid cancer in 2015 was 14.6 per 100,000, nearly three times higher than that in 2005, and it has become the fourth most common malignant tumor among women (Zheng et al. 2019). Although most of thyroid cancer patients with a favorable 10 -year overall survival rate, above $20 \%$ of patients remain at risk of tumor recurrence for several years after operation (Dong et al. 2019). In addition, thyroid cancer may produce numerous serious clinical symptoms, including hoarseness, trouble breathing and swallowing, and Horner Syndrome caused by sympathetic nerve compression (Kim et al. 2017).

The increasing incidence of thyroid cancer may partly be accounted for advanced diagnostic technology, which leads to an elevated detection rate of occult thyroid cancer (Warrick and Lengerich 2019). However, 
there is evidence that not only thyroid cancer $<1 \mathrm{~cm}$ but diameters $>4 \mathrm{~cm}$ present an obvious increasing rate (Wang and Wang 2015). Moreover, some of the traditional risk factors for thyroid cancer still could not explain this epidemic dynamic situation, including sex, radiation exposure, abnormal iodine intake, a family history of thyroid disease and metabolic syndrome (Kitahara et al. 2018; Rubio et al. 2018). In view of the severe situation of TC prevention and control, it is urgent to explore the relevant pathogenic factors of TC (Zhang et al. 2020). The occurrence of thyroid cancer is the result of interaction between heredity and environment, so the influence of environmental factors cannot be ignored.

Chlorophenols (CPs), a class of aromatic chlorinated compound whose hydrogen atoms on the benzene ring, was replaced by chlorine atoms, widely exists in aquatic environment, atmosphere, sediment and soil. CPs were important raw materials in chemical production and were widely used in industry and agriculture. Among them, 2,4-dichlorophenol (2,4-DCP) was put into mass production for pesticide production, and 2,4,6trichlorophenol (2,4,6-TCP) was mainly used as fungicide and dye intermediate (Zhang et al., 2018). Pentachlorophenol (PCP) was a common estrogen-like aromatic compound, which has been widely used in insecticides, fungicides, herbicides, wood preservatives and chemical manufacturing (Cheng et al. 2015; Cui et al. 2017). EPA estimated that $10063 \mathrm{~kg}$ of 2,4-DCP and $4295 \mathrm{~kg}$ of PCP were released into the environment in 2014 (ECCC and HC, 2016). Studies have shown that PCP levels in surface water/sediments in China increase over time (Zheng et al. 2012). The reason is that sodium pentachlorophenol (Na-PCP) has been widely sprayed since 1960 to control the spread of schistosomiasis, and later in China is higher than in other countries. The annual production of pentachlorophenol reached about 3,000 tons in 2000 (Tan and Zhang 2008; Zheng et al. 2013).

The continuous use of CPs compounds in countries around the world suggests that it may further exacerbate environmental pollution and pose potential risks to human health. After entering the human body, CPs can produce a strong interference to the endocrine system, affect the synthesis and metabolism of hormones in the body, and have a certain negative impact on the immune mechanism of the human body (Orton et al. 2009). Up to now, exposure to chlorophenols has been successively reported to be associated with the incidence of various malignant tumors, such as gastric cancer, breast cancer, ovarian cancer and colorectal cancer (Cheng et al. 2015; Dorgan et al. 1999; Sharma et al. 2019). The International Agency for Research on Cancer and the U.S. Environmental Protection Agency classified PCP as a group 2B carcinogen (IARC 1999). Accumulating evidence suggests associations between CPs exposure and adverse health outcome in thyroid. Animal studies in zebra fish indicate that long-term exposure to PCP can alter thyroid hormone and mRNAs $(\operatorname{tsh} \beta, \operatorname{tr} \beta$, dio1, dio2) in thyroid hormone pathway (Guo and Zhou 2013). Kawaguchi et al. found that when mice were exposed to CPs, the expression of thyroid hormone receptor 1 and brain synaptic protein I was inhibited, leading to impaired thyroid function (Kawaguchi et al. 2008). In addition, the field epidemiological survey (Cui et al. 2017) also indicated that the incidence of TC in community residents increased significantly after exposure to medium and high doses of PCP. However, evidence is rather limited and divided in regard to the effect of CPs on thyroid cancer. Whether actual exposure to CPs causes thyroid cancer remains unknown.

This is the first study to investigate the effects of three chlorophenols on thyroid cancer. In this study, a 1:1 matched case-control study design was used to collect 297 TC case-controls from Anhui Provincial Cancer Hospital, First Affiliated Hospital of Anhui Medical University, Second Affiliated Hospital of Anhui Medical University from August 2017 to September 2019, and laboratory tests were conducted to determine the levels 
of three CPS in urine. Conditional logistic regression model and restricted cubic spline function were used to investigate the potential association between CPS exposure and TC incidence.

\section{Materials And Methods}

\subsection{Study population}

The study participants were recruited continuously from June 2017 to September 2019 in Hefei, Anhui Province, China. Cases were defined as patients who having a definite pathological diagnosis of thyroid cancer, selected from Otolaryngology-Head \& Neck surgery departments of First Affiliated Hospital of Anhui Medical University, Second Affiliated Hospital of Anhui Medical University and Anhui Provincial Cancer Hospital. Cases who suffered from severe hepatic and renal dysfunction, malignant anemia and mental disorder were excluded. Given the abnormal thyroid hormone level in pregnancy duration, pregnant women were also excluded from this study. Meanwhile, appropriate controls were selected from newly admitted patients collected from non-endocrinology departments of the above three hospitals. In this study, individuals were paired 1:1 according to gender and age ( \pm 5 years old).Controls were restricted to individuals with no history of malignant tumors or thyroid disease verified by their biochemical test. Subjects who have receive thyroid-related medication such as euthyrox and adrenocortical hormone were also excluded. Ultimately, a total of 297 thyroid cancer patients comprised the case group and 297 corresponding controls were selected.

This study was approved by Anhui Medical University Biomedical Ethics Committee (Approval No. 20170305) and was in accordance with the principle of the Helsinki Declaration and its later amendments or comparable ethical standards. Informed consent was obtained from all individual participants included in the study. Prior to the research, subjects completed an informed consent form.

\subsection{Data collection}

Structured questionnaires were adopted to record information by trained and qualified investigators, including socio-demographics, behavior habits, lifestyle, radioactive exposure, and family history of malignant tumor and thyroid disease. The height $(\mathrm{m})$ and weight $(\mathrm{kg})$ of the participants were measured and the body mass index (BMI) was calculated based on the formula: weight / the square of height. Clinical and pathologic information for the cases was obtained by reviewing of medical records, including thyroid cancer subtypes, primary tumor size, tumor metastasis (lymph node metastasis or distant metastasis), multifocality of tumors (solitary or multifocal).

Peripheral blood samples were obtained from each participant by professional nursing staff after an overnight fast for at least $8 \mathrm{~h}$. The serum was separated by centrifugal machine and stored in $-80^{\circ} \mathrm{C}$ refrigerator until further analysis. Serum free triiodothyronine (FT3), free thyroxine (FT4) and thyroid stimulating hormone (TSH) was tested using electrochemiluminescence immunoassay (Cobas e411, Roche Diagnostics, Germany). All measurements were in accordance with the instructions of experimental instruments and kits.

2.3 Urinary CPs measurement 
Considering the photolysis property of CPs, first-morning urine samples were collected by a $50 \mathrm{ml}$ centrifuge tube and keep in a portable specimen box during transport to avoid any contact with direct sunlight. Then samples were transferred to the laboratory and preserved at $-80{ }^{\circ} \mathrm{C}$ refrigerator until analysis. Urine value of CPs concentration was measured by gas chromatography-tandem mass spectrometry (GC/MS, Agilent 7890A, USA) with a HP-5MS column (30m × 0.25mm × 0.25mm, Agilent Co., USA). The procedures for pretreatment of urine samples are as following: A $10 \mathrm{ml}$ urine sample was taken and 2-3 drops of concentrated hydrochloric acid were absorbed with a glass dropper to adjust $\mathrm{PH}$ to acid-stage. All the samples to be tested were uniformly added with 2,4,6-TBP $(5 \mathrm{mg} / \mathrm{L})$ internal standard of $200 \mu \mathrm{L}$ and mixed. To prevent emulsification, sodium chloride is added to the solution until saturated. In the liquid-liquid extraction step, the n-hexane (Teida, USA) was used. We draw the n-hexane layer into another $50 \mathrm{ml}$ centrifuge tube and add 10 $\mathrm{mL}$ of $\mathrm{n}$-hexane for extraction again. After that, the extract liquor of $\mathrm{n}$-hexane was fully combined. In the combined extract, $2 \mathrm{ml} 0.3 \mathrm{~mol} / \mathrm{L}$ potassium carbonate solution was added, followed by $1 \mathrm{ml}$ acetic anhydride, Then the mixed solution was placed in a constant temperature water bath at $65^{\circ} \mathrm{C}$ for derivative reaction. After derivatization, the sample was dehydrated with anhydrous sodium sulfate, and $1.5 \mathrm{ml}$ was taken in the brown sample injection bottle to be tested.

Creatinine determination is mainly used to correct the concentration of CPs in urine. Picric acid colorimetric method was used to determine urine creatinine by Beckman DXC800 automatic biochemical analyzer. Arsenic - cerium catalytic spectrophotometry was used to detect the level of urinary iodine (WS/T107.1-2016).

\subsection{Statistical analysis}

Statistical analysis was performed using R 3.6.3 and SPSS 23.0 software. Basic characteristics of cases and controls were compared using two independent sample t-test for normally distributed data or Wilcoxon signed-rank tests for skewed distribution variables, and chi-square tests were used for categorical variables. To explore the distribution of urinary CPs concentration in cases group based on different clinical pathologic characteristics, such as tumor subtypes, maximum tumor diameter $(\leq 1 \mathrm{~cm}$ or $\nabla 1 \mathrm{~cm})$, tumor site (unilateral or bilateral), tumor metastasis (yes or no) and tumor multifocality (solitary or multifocal), CPs were logtransformed and Mann-Whitney U tests was employed.

We adopted conditional logistic regression models to estimate adjusted odds ratios (ORs) and 95\% confidence intervals (Cls) for thyroid cancer and CPs categorized into quartiles according to their concentration distributions among the control group. Potential confounders were thoroughly taken into consideration in different regression models, including, BMI (continuous), household income ( $\leq 30000 \mathrm{CNY}$, 30001-59999CNY, $\geq 60000 \mathrm{CNY}$ ), living conditions (live together, solitary), alcohol consumption (yes or no), family history of thyroid disease (yes or no), family history of malignant tumor (yes or no), urinary iodine (continuous). Linear trend p-values were derived by entering the quartiles of creatinine standardized CPs concentrations into the models as an ordinal categorical variable. Stratified analyses were performed based on different pathologic characteristics, including tumor subtypes, tumor diameter, tumor site, tumor metastasis and multifocality.

In order to explore the possible nonlinear relationship between CPs and thyroid cancer risk, restricted cubic spline function model was used. The concentrations of CPs in urine after natural logarithmic conversion were 
analyzed as continuous variables, entering into the restricted cubic spline function model with 3 knots (located at the 10th, 50th and 90th percentiles) in each group, respectively. The value of chlorophenols in the 10th percentile was chosen for the reference value. In addition, the models were adjusted for BMI, household income, living conditions, drinking, family history of thyroid disease, family history of malignant tumor and urinary iodine. $P$ values were two sided, and $P<0.05$ was defined as statistical significance.

\section{Results}

3.1 General demographic information and pathologic characteristics of subjects

Table 1 presents selected demographic and lifestyle characteristics of cases and controls, as well as clinical pathologic characteristics. A total of 594 subjects were enrolled with age and sex matched, including 297 cases and 297 controls. Female patients accounted for $68.7 \%$ of the total cases of thyroid cancer. Compared with the control participants, the mean BMI of cases was higher, after grouping BMI, the case group had a higher proportion of BMI in the 24.0-27.9 group compared with the control group. In terms of family income, living conditions and alcohol consumption, the differences between the two groups were statistically significant $(P<0.05)$. Additionally, subjects in cases group were apt to have a family history of thyroid disease and malignancy than controls. For education level, smoking status, exercise frequency and history of radiation exposure, no statistical significance was observed.

\subsection{The concentration distribution of biochemical indexes in cases and controls}

The concentration distribution of biochemical indexes in case and control groups was presented in Table 2 . Without creatinine correction, the median concentrations of 2,4-DCP, 2,4,6-TCP and PCP in the case group were $0.68 \mu \mathrm{g} / \mathrm{L}, 0.36 \mu \mathrm{g} / \mathrm{L}$ and $0.63 \mu \mathrm{g} / \mathrm{L}$, respectively. while those in the control group were $0.50 \mu \mathrm{g} / \mathrm{L}, 0.24$ $\mu \mathrm{g} / \mathrm{L}$ and $0.41 \mu \mathrm{g} / \mathrm{L}$, respectively. After creatinine correction, the median concentrations of 2,4-DCP, 2,4,6 TCP and PCP in the case group were $0.67 \mu \mathrm{g} / \mathrm{g}, 0.34 \mu \mathrm{g} / \mathrm{g}$ and $0.62 \mu \mathrm{g} / \mathrm{g}$, while those in the control group were $0.51 \mu \mathrm{g} / \mathrm{g}, 0.26 \mu \mathrm{g} / \mathrm{g}$ and $0.39 \mu \mathrm{g} / \mathrm{g}$, respectively. It is worth noting that subjects with thyroid cancer had higher levels of both concentration of urinary CPs and creatinine-adjusted CPs than those without thyroid cancer. The median urinary iodine concentration was $255.76 \mu \mathrm{g} / \mathrm{L}$ in the case group and $209.08 \mu \mathrm{g} / \mathrm{L}$ in the control group. The median urinary iodine concentration after creatinine correction was $297.78 \mu \mathrm{g} / \mathrm{g}$ and $197.54 \mu \mathrm{g} / \mathrm{g}$, respectively.

3.3 The association between Chlorophenols and thyroid cancer

Results of the association of CPs exposure with the risk of thyroid cancer was presented in table 3 . For 2,4DCP, compared with participants in the first quartile, the OR for those in the fourth quarter was 2.28 (95\% Cl: 1.24-4.18) with adjustment for, BMI, household income, living conditions, alcohol consumption, urinary iodine, family history of thyroid disease and malignant tumor. After adjusting for these confounding factors, the risk of thyroid cancer was increased by $209 \%$ (95\% Cl: 1.66-5.77) and 230\% (95\% Cl: 1.71-6.36) for trichlorophenol and pentachlorophenol, respectively. Given that papillary thyroid carcinoma accounted for $92.9 \%$ of the total cases and was the main subtype of thyroid cancer, we performed a subgroup analysis of papillary thyroid carcinoma patients and the results were shown in Supplementary Table 1. For PCP, the adjusted ORs in third and fourth quartile were 2.48 (95\% Cl: 1.22-5.04), and 3.82 (95\% Cl: 1.83-7.99). 
In order to clarify the relationship between three CPs and TC risk more comprehensively, the restricted cubic spline function was used for smoothing curve fitting. The nonlinear correlation between 2,4-DCP, 2,4,6 TCP, PCP and TC could be displayed by setting spline function nodes, and the restricted cubic spline function model of the total population was drawn respectively. After the natural logarithmic transformation of the concentrations of three CPs, the results showed that for 2, 4-DCP and 2,4,6 TCP, the risk of TC incidence increased with the increase of the concentrations, and showed significant linear correlations. It can be seen from Fig 1 that at low concentrations, the correlation between PCP and TC increases with the increase of concentration, and decreases slightly with the further increase of concentration. Some studies have shown that there was a significant gender difference in TC risk. Therefore, the population was divided into male and female groups, and the restricted cubic spline models were carried out to find the difference. The associations of 2, 4-DCP and 2,4,6 TCP with thyroid cancer risk in the male and female subgroups were consistent with the overall population. In the male group, thyroid cancer increased with increased PCP concentration. However, in the female group, the risk of incidence first decreased with the increase of concentration, but with the further increase of concentration, the risk of incidence of TC increased significantly (see from supplementary Fig 1).

3.5 The relationship between chlorophenols and the risk of thyroid cancer with different pathological characteristics

In order to investigate the risk of 2,4-DCP, 2,4,6 TCP, PCP and TC with different tumor diameter, the tumor diameter of TC was divided into two categories: $>1 \mathrm{~cm}$ and $\leq 1 \mathrm{~cm}$, and the subgroup analysis was performed by conditional logistic regression model. Table 4 showed a significant correlation between TC and 2,4,6 TCP $(\mathrm{OR}=1.68,95 \% \mathrm{Cl}: 1.10-2.56)$ in the group with $\mathrm{TC}$ diameter $>1 \mathrm{~cm}$, after adjusting for related confounding factors. Compared with the first fractional concentration, the third and fourth fractional concentration of PCP was significantly correlated with the incidence of TC with tumor diameter of $>1 \mathrm{~cm}(\mathrm{OR}=2.86,95 \% \mathrm{Cl}: 1.02-$ $8.00)$ and $(\mathrm{OR}=3.24,95 \% \mathrm{Cl}: 1.20-8.76)$. As shown in supplementary Fig 2 , the restricted cubic spline function was used for smoothing curve fitting to obtain the relationship between the three types of CPS and TC risk of different tumor diameters $\>1 \mathrm{~cm}$ and $\leq 1 \mathrm{~cm} \Downarrow$.

2,4-DCP at the fourth quartile concentrations increased the incidence of metastatic TC by $306 \%$ (OR $=4.06$, 95\%Cl: 1.68-9.81). Meanwhile, 2,4,6 TCP at the third and fourth quantile concentrations were positively correlated with the incidence of metastatic TC (OR=3.96, 95\%Cl: 1.53-10.24; OR=7.78, 95\%Cl: 2.78-21.74). Notably, urinary PCP concentration was statistically associated with the risk of thyroid cancer in both metastatic and non-metastatic thyroid cancers (see from Table 5).Supplementary Fig 3 shows the relationship between the three CPS and the metastatic and non-metastatic TC risks by smoothing curve fitting using the restricted cubic spline function.

Based on the location of primary tumor, it was divided into unilateral TC and bilateral TC. Supplementary Table 2 presented that there were no significant correlations between CPs and the incidence of unilateral and bilateral TC (P-trend > 0.05). However, in the unilateral TC subgroup, the risk of disease first increased with the increase of PCP concentration, and then decreased with the increase of PCP concentration; In the bilateral TC 
subgroup, the risk of morbidity increased first with the increase of 2,4,6-TCP concentration, and then decreased with the increase of the concentration (see from supplementary Fig 4).

According to the number of lesions, they were divided into unifocal TC and multifocal TC. Supplementary Table 3 showed that 2,4,6 TCP was significantly correlated with the incidence of single focal TC (OR=2.70, $95 \% \mathrm{Cl}: 1.20-6.05)$. Only in the fourth quartile of PCP concentration was observed significant association in multifocal TC group, with OR value of 5.12 (95\% Cl: 1.56-16.74). In supplementary Fig 5, as PCP concentration increased, the risk of unifocal TC showed an approximately inverted U-shaped pattern.

\section{Discussion}

In recent years, with the development of economy, environmental pollution has become more and more serious. CPs is an important raw material in chemical production, widely used in pesticides, herbicides and preservatives, etc. With decades of use, CPs substances have been deposited in large quantities in the environment and posed a great threat to human health. This study investigated the association between CPs exposure level and thyroid cancer risk, and found that high urine concentrations of 2,4-DCP, 2,4,6-TCP and PCP are positively correlated with the incidence of thyroid cancer. After drawing the restricted cubic spline function and fitting the smooth curve, the results showed that the risk of thyroid cancer increased with the increase of CPs concentration, showing a certain dose-response relationship. In the thyroid cancer group with tumor diameter $>1 \mathrm{~cm}$, the changes of 2,4,6 TCP and PCP concentrations were significantly associated with the risk of thyroid cancer. At the same time, urinary concentrations of 2,4-DCP, 2,4,6 TCP and PCP were positively correlated with the risk of metastatic thyroid cancer.

So far, there are few studies on the correlation between CPs and TC risk at home and abroad. Cui et al. (2017) found similar conclusions in the field study. Based on the national standard population in 2010, the standardized rate ratio (SRR) of thyroid cancer in the total population exposed to the moderate PCP group was $1.49,95 \% \mathrm{Cl} 1.26-1.76$. In addition, the SRR of thyroid cancer in women group exposed to the moderate dose of PCP was 1.79, 95\% Cl: 1.60-2.01, the SRR of women in the high PCP group was 1.32, 95\% Cl: 1.171.48. In addition, a cohort study in the United States (Ruder 2011) followed up 2122 PCP producing workers and found that the expected standard mortality rate of thyroid cancer caused by long-term exposure to PCP was 0.49. However, Rooney et al. (2018) did not find a significant correlation between 2,4-DCP and thyroid disease. Similarly, Wei et al. (2016) pointed out that 2,4-DCP had no statistical effect on FT3, FT4 and TSH, while the homolog of 2,4-DCP, 2,5-DCP, might be associated with thyroid dysfunction to some extent in their study on CPs exposure and thyroid function in American adolescents. Therefore, the relationship between CPS and TC is still unclear. This study can fill the gaps in the research on the relationship between CPs and TC to a certain extent, but the relevant conclusions still need to be verified in large-scale cohort studies and experimental studies.

The relationship between human exposure to CPS and increased TC risk remains unclear. A number of experimental studies have shown that estrogen plays a key role in the pathogenesis of TC (Rubio et al. 2018; Xue et al. 2019). Yu et al. (2014) founded that PCP showed an antagonistic effect against thyroid hormone receptor at a concentration of $10^{-5} \mathrm{M}$, while 2,4,6-TCP showed an anti-estrogen effect. Yin et al. (2008) used denaturing high performance liquid chromatography and DNA sequencing analysis methods to prove that 
zebrafish exposed to 2,4,6-TCP at a rate of $5 \mathrm{mg} / \mathrm{L}$ for 10 days would lead to the increase of point mutation of p53 gene in liver genome, thus participating in the carcinogenesis process of organism by inducing point mutation of somatic genome. Normal thyroid development depends on a balanced hormonal environment. CPS have similar molecular structure to estradiol, endowing it with the ability to bind estrogen receptor $a$ or $\beta$, thus exerting thyroid interference effect and destroying the normal level of estrogen, eventually leading to the occurrence of TC.

In fact, another widely accepted mechanism for causing TC is the HPT axis injury theory. The experiments on zebrafish (Yu et al. 2014) show that PCP exposure can reduce the expression of T4 receptor mRNA in the brain, and change the mRNA levels of deiodinase, cytoplasmic sulfur transferase and thyroxine gene in the liver. Long term exposure to PCP will change the plasma T4 level and change the gene expression related to thyroid hormone signal and metabolism in HPT axis, resulting in abnormal development of zebrafish. Guo et al. (2013) verified the interfering effect of CPs on thyroid gland in vivo and in vitro experiments. The results of in vitro experiments showed that when the rat pituitary $\mathrm{GH} 3$ cells were exposed to PCP at a concentration of $1.0 \mathrm{M}$, they could significantly down-regulate the basal transcription and T3-induced Dio1 transcription, indicating that PCP has antagonistic activity in vitro. In vivo experiments, PCP exposure resulted in decreased T4 level and increased T3 level in zebrafish. Meanwhile, PCP exposure significantly upregulated the mRNA expression of genes on the HPT axis, including thyroid stimulating hormone, sodium/iodide synthase, thyroglobulin, Dio1 and Dio2, thyroid hormone receptors, and uridine diphosphate glucuronic acid transferase.

The exercise of normal thyroid function not only depends on the appropriate level of thyroid hormone, but also requires the body to be in a normal immune state. Studies have shown that the immune system plays a decisive role in carcinogenesis. In an animal experiment in India, white blood cells were used for cell apoptosis and mitochondrial membrane potential analysis, and propidium iodide staining and rhodamine 123 staining were used. The influence of DCP on cell cycle and mitochondrial membrane permeability was analyzed by flow cytometry. The results showed that DCP reduced mitochondrial membrane potential, changed cell cycle, and confirmed that DNA damage caused apoptosis of immune system cells (Lone et al. 2017). Nnodu et al. (2008) pointed out that CPs can reduce ATP level in the body, thereby reducing the tumor killing function of natural killer cells and promoting the occurrence of tumors. However, relevant studies also drew different conclusions. The results in the experiment of rats (Blakley et al. 1998) indicated that when studying the effects of PCP on the immune function of rats, the evidence of PCP induced humoral immune injury was not obvious, and the lymphocyte budding effect observed after PCP exposure was not related to phagocytosis or the expression of lymphocyte surface antigen.

In recent years, the relationship between thyroid disease and oxidative stress has attracted more and more attention. Studies have shown that EEDs can destroy cellular biological energy, reduce the production of ATP, and inhibit the complex activity of mitochondria and aerobic respiration (Al-Ghafari et al. 2019). At the same time, the cellular redox defense system is progressively depleted by reducing sod and catalase activity and intracellular glutathione levels. Some environmental pollutants with redox properties, such as CPs herbicides and some aromatic compounds, can increase the content of reactive oxygen species in the body. These environmental pollutants can catalyze the redox reaction in organism, and cause oxidative damage to organisms. Animal experiments (Zhang et al. 2014) showed that 2,4,6-TCP can induce oxidative stress, endoplasmic reticulum stress and cell apoptosis in vitro, which together lead to the generation of cytotoxicity 
and promote the occurrence of malignant tumors. Due to the structure similar to natural hormones, CPs can mimic the formation of hormones in vivo, interfere with the synthesis and metabolism of hormones, and then interfere with some signal pathways and related enzyme reactions of oxidative stress response, causing serious oxidative damage to cells. In view of the close relationship between CPs and TC, oxidative stress should be further studied as an endogenous factor leading to increased thyroid hyperplasia.

This study found that in the group with thyroid cancer diameter $>1 \mathrm{~cm}$, increased concentrations of 2,4,6 TCP and PCP were significantly associated with the risk of thyroid cancer. Urinary concentrations of 2,4-DCP, 2,4,6 TCP and PCP were positively correlated with the risk of metastatic thyroid cancer, suggesting that the high exposure level of CPs may be related to the progression of thyroid cancer. The relationship between CPS and the progression of thyroid cancer is not clear, but bisphenol A and polybrominated diphenyl ethers with similar structure and endocrine disrupting effect with PCP have been confirmed to be related to the proliferation, migration and invasion of tumor cells (Allen et al. 2016). The experimental results (Zhang et al. 2017) showed that such endocrine disruptors could target intracellular signals involved in the development of thyroid cancer and promote the proliferation of thyroid cells. Low dose exposure can not only produce estradiol like effect by binding estrogen receptor $a$ and $\beta$, but also activate AKT/mTOR pathway by binding estrogen receptor membrane receptor, and finally affect the expression of related genes, promote the proliferation of thyroid cancer cell BHP10-3, and enhance the invasion of thyroid adenocarcinoma.

Our study has several strengths. To the best of our knowledge, this study was the first study to systematically research the association between the exposure levels of CPs with thyroid cancer risk. As we all know, since 1960, the Na-PCP had been extensively sprayed to control the spread of snail borne schistosomiasis in China, thus paid a heavy price for environmental pollution and become the most concerned environment problem. For the present research, we focused on the effects of non-occupational exposure to PCP and its homologues in individual urinary sample on TC risk in Chinese population. This could provide little but valuable suggestion for public health department in China. Then, we collected detailed information on potential confounding factors, which were used to conduct detailed analysis in different adjusting models, and restricted cubic spline function were used to explore the non-liner relationship. In addition, we adopted strict quality control procedures in data collection and accurate internal standard method was added into laboratory detection to reduce the potential of bias. Last but not least, we analyzed the relationship between the exposure levels of CPs and the incidence of thyroid cancer with different pathological types, in order to explore the effect of CPS on the progression of thyroid cancer.

Several limitations need to be noticed. Firstly, the primary potential limitation to our study is the use of single spot urinary PCP measurements. Although PCP has a long biological half-life and persistence characteristic, the multiple spot urine samples may be a better reflection of long-term exposure due to the metabolism and excretion of PCP in human body. However, this chemical of PCP was detected above $85 \%$ of samples in our study, suggesting that PCP is continuous and ubiquitous. In addition, it has been proved that single spot sample may be a reliable predictor for long-term exposure of PCP (Wang et al. 2016). Secondly, this study failed to measure estrogen as a biomarker, so it was limited in the validation of the correlation between estrogen, CPS and TC. Thirdly, most of the TC patients included in this study were PTC, and due to the insufficient sample size of other subtypes, detailed analysis of subtypes becomes unrealistic, which also makes the analysis not comprehensive enough. In addition, although a sequence of likely confounding 
factors was taken into consideration in conditional regression analysis, such as BMI, household income level, living conditions, alcohol consumption, family history of thyroid disease, family history of malignant tumor and urinary iodine, FT3, FT4 and TSH, some potential confounding variables were still out of consideration. For example, it has been demonstrated that exposure to radiation in childhood could be a vital carcinogenic factor (Lubin et al. 2017). However, due to the long interval, the subjects could not accurately recall the relevant information, which needed to be improved in the follow-up study. Finally, because of the nature of a retrospective research, the ability of causal inference was limited and future prospective studies are warranted to conclude a causal relationship.

\section{Conclusion}

In summary, urinary concentrations of 2,4-DCP, 2,4,6-TCP and PCP were positively correlated with TC and presented dose-response relationship. This study also found that 2,4,6-TCP and PCP had certain effects on the invasiveness of thyroid tumor. Further studies are needed to confirm our findings, and to evaluate potential mechanisms that might be responsible for the association between CPs exposure and TC risks. In addition, the health department should be vigilant, not only to pay attention to the sharp rise of TC, but also to prevent the environmental pollution of CPs. The government should formulate relevant policies as soon as possible and do a good job in prevention and control.

\section{Declarations}

\section{Ethics approval and consent to participate}

This study was approved by the Ethical Committee of Anhui Medical University, China. All participants signed a written informed consent form prior to participating.

\section{Consent for publication}

\section{Availability of data and materials}

The datasets analyzed during the current study are available from the corresponding author on reasonable request.

\section{Conflicts of interest}

The authors declares that there are no conflicts of interest.

\section{Funding}


This work was supported by Academic Aid Project for Top Talents (Professionals) in Colleges and Universities of Anhui Province (gxbjZD09), the Project for Anhui Province Academic Technology Leader Reserve Candidates' Academic Research Activities (2017H108), and the National Key Research and Development Program (NO. 2016YFC1302605).

\section{Author's contributions}

WJY and FH collaboratively designed the study, both making substantial intellectual contributions. WJY analyzed the data and drafted the manuscript together with HBW, and CZ『QZ and FH revised the manuscript. $\mathrm{MJH}, \mathrm{GAL}$ and ZYZ all contributed in interpreting the data. JLZ, HHZ ,HSZ and WJY all contributed in collecting the data. WJY and HBW contributed equally. All authors read and approved the final manuscript.

\section{Acknowledgements}

We would like to thank all the subjects who participated in this research. This work was supported by Academic Aid Project for Top Talents (Professionals) in Colleges and Universities of Anhui Province (gxbjZD09), the Project for Anhui Province Academic Technology Leader Reserve Candidates' Academic Research Activities (2017H108), and the National Key Research and Development Program (NO. 2016YFC1302605). All authors read and approved the final manuscript.

\section{References}

Al-Ghafari A, Elmorsy E, Fikry E, Alrowaili M, Carter WG (2019) The heavy metals lead and cadmium are cytotoxic to human bone osteoblasts via induction of redox stress. PLoS. ONE. 14(11), e0225341. https://doi.org/10.1371/journal.pone.0225341.

Allen JG, Gale S, Zoeller RT, Spengler JD, Birnbaum L, McNeely E (2016) PBDE flame retardants, thyroid disease, and menopausal status in U.S. women. Environ. Health. 15(1), 60. https://doi.org/10.1186/s12940016-0141-0.

Blakley BR, Yole MJ, Brousseau P, Boermans H, Fournier M (1998) Effect of pentachlorophenol on immune function. Toxicology. 125(2-3), 141-148. https://doi.org/10.1016/s0300-483x(97)00154-6.

Cheng P, Zhang Q, Shan X, Shen D, Wang B, Tang Z, Jin Y, Zhang C, Huang F (2015) Cancer risks and longterm community-level exposure to pentachlorophenol in contaminated areas, China. Environ. Sci. Pollut. Res. Int. 22(2), 1309-1317. https://doi.org/10.1007/s11356-014-3469-4.

Cui Y, Liang L, Zhong Q, He Q, Shan X, Chen K, Huang F (2017) The association of cancer risks with pentachlorophenol exposure: Focusing on community population in the areas along certain section of Yangtze River in China. Environ. Pollut. 224, 729-738. https://doi.org/10.1016/j.envpol.2016.12.011. 
Dong W, Horiuchi K, Tokumitsu H, Sakamoto A, Noguchi E, Ueda Y, Okamoto T( 2019) Time-Varying Pattern of Mortality and Recurrence from Papillary Thyroid Cancer: Lessons from a Long-Term Follow-Up. Thyroid. 29(6), 802-808. https://doi.org/10.1089/thy.2018.0128.

Dorgan JF, Brock JW, Rothman N, Needham LL, Miller R., Stephenson HE, Schussler, N, Taylor PR.( 1999) Serum organochlorine pesticides and PCBs and breast cancer risk: results from a prospective analysis (USA). Cancer. Causes. Control. 10(1), 1-11. https://doi.org/10.1023/a:1008824131727.

Environment and Climate Change Canada/Health Canada (2016) Assessment Report Triclosan. http://www.ec.gc.ca/ese-ees/default.asp?lang=En\&n=65584A12-1.

Guo Y, Zhou B (2013) Thyroid endocrine system disruption by pentachlorophenol: An in vitro, and in vivo, assay. Aquat. Toxicol. 142-143, 138-145. https://doi.org/10.1016/j.aquatox.2013.08.005.

IARC (International Agency for Research on Cancer) (1999) Polychlorophenols and their sodium salts. IARC. Monogr. Eval. Carcinog. Risks. Hum. 2, 769-816. http://www.inchem.org/documents/iarc/vol71/028polychloroph.html.

Kato E, Niebuhr DW (2018) Screening for Thyroid Cancer. Am. Fam. Physician. 97(6), 406-407.

Kawaguchi M, Morohoshi K, Saita E, Yanagisawa R, Watanabe G, Takano H, Morita M, Imai H, Taya K, Himi T (2008) Developmental exposure to pentachlorophenol affects the expression of thyroid hormone receptor beta1 and synapsin I in brain, resulting in thyroid function vulnerability in rats. Endocrine. 33(3), $277-284$. https://doi.org/10.1007/s12020-008-9086-6.

Kim C, Lee JH, Choi YJ, Kim WB, Sung TY, Baek JH (2017) Complications encountered in ultrasonographyguided radiofrequency ablation of benign thyroid nodules and recurrent thyroid cancers. Eur Radiol. 27(8), 3128-3137. https://doi.org/10.1007/s00330-016-4690-y.

Kitahara CM, Preston DL, Neta G, Little MP, Doody MM, Simon SL, Sigurdson AJ, Alexander BH, Linet MS (2018) Occupational radiation exposure and thyroid cancer incidence in a cohort of U.S. radiologic technologists, 1983-2013. Int. J. Cancer. 143(9), 2145. https://doi.org/10.1002/ijc.31270.

Lone MI, Nabi A, Dar NJ, Hussain A, Nazam N, Hamid A, Ahmad W (2017) Toxicogenetic evaluation of dichlorophene in peripheral blood and in the cells of the immune system using molecular and flow cytometric approaches. Chemosphere. 167, 520-529. https://doi.org/10.1016/j.chemosphere.2016.08.131.

Lubin JH, Adams MJ, Shore R, Holmberg E, Schneider AB, Hawkins MM, Robison LL, Inskip PD, Lundell M, Johansson R, Kleinerman RA, de Vathaire F, Damber L, Sadetzki S, Tucker M, Sakata R., Veiga LHS (2017) Thyroid Cancer Following Childhood Low-Dose Radiation Exposure: A Pooled Analysis of Nine Cohorts. J. Clin. Endocrinol. Metab. 102(7), 2575-2583. https://doi.org/10.1210/jc.2016-3529.

Nnodu U, Whalen MM (2008) Pentachlorophenol decreases ATP levels in human natural killer cells. J. Appl. Toxicol. 28(8), 1016-1020. https://doi.org/10.1002/jat.1367. 
Orton F, Lutz I, Kloas W, Routledge EJ (2009) Endocrine Disrupting Effects of Herbicides and Pentachlorophenol: In Vitro and in Vivo Evidence. Environ. Sci. Technol. 43(6), 2144-2150. https://doi.org/10.1021/es8028928.

Rooney MR, Lutsey PL, Bhatti P, Prizment A (2018) Urinary 2,5-dicholorophenol and 2,4- dichlorophenol concentrations and prevalent disease among adults in the National Health and Nutrition Examination Survey (NHANES). Occup. Environ. Med. 76(3), 181-188. https://doi.org/10.1136/oemed-2018-105278.

Rubio GA, Catanuto P, Glassberg MK, Lew JI, Elliot SJ (2018) Estrogen receptor subtype expression and regulation is altered in papillary thyroid cancer after menopause. Surgery. 163(1), 143-149. https://doi.org/10.1016/j.surg.2017.04.031.

Ruder AM (2011) Mortality of US pentachlorophenol production workers through 2005. Chemosphere. 83(6), 851-861. https://doi.org/10.1016/j.chemosphere.2011.02.064.

Sharma T, Banerjee BD, Thakur GK, Guleria K, Mazumdar D (2019) Polymorphism of xenobiotic metabolizing gene and susceptibility of epithelial ovarian cancer with reference to organochlorine pesticides exposure. Exp. Biol. Med. (Maywood). 244(16), 1446-1453. https://doi.org/10.1177/1535370219878652.

Siegel RL, Miller KD, Jemal A (2018) Cancer statistics (2018) CA. Cancer. J. Clin. 60(5), 277-300. https://doi.org/10.3322/caac.21442.

Tan D, Zhang JB (2008) Estimates of PCP-Na consumption in districts and provinces in China by the Topdown calculation method. Environ. Pollut. Control. 30, 17-20. (in Chinese).

US EPA (U.S. Environmental Protection Agency) (1991) Pentachlorophenol. US EPA. CASRN 87-86-5. Available: http://www.epa.gov/iris/subst/0086.htm.

Wang Y, Wang W (2015) Increasing incidence of thyroid cancer in Shanghai, China, 1983-2007. Asia. Pac. J. Public. Health. 27(2), NP223-9. https://doi.org/10.1177/1010539512436874.

Wang YX, Feng W, Zeng Q, Sun Y, Wang P, You L, Yang P, Huang Z, Yu SL, Lu WQ (2016) Variability of Metal Levels in Spot, First Morning, and 24-Hour Urine Samples over a 3-Month Period in Healthy Adult Chinese Men. Environ. Health. Perspect. 124(4), 468-476. https://doi.org/10.1289/ehp.1409551.

Warrick J, Lengerich E (2019) Thyroid Cancer Overdiagnosis and Malpractice Climate. Arch. Pathol. Lab. Med. 143(4), 414-415. https://doi.org/10.5858/arpa.2018-0490-LE.

Wei Y, Zhu J (2016) Para-Dichlorobenzene Exposure Is Associated with Thyroid Dysfunction in US Adolescents. J. Pediatr. 177, 238-243. https://doi.org/10.1016/j.jpeds.2016.06.085.

Xue L, Yan H, Chen Y, Zhang Q, Xie X, Ding X, Wang X, Qian Z, Xiao F, Song Z, Wu Y, Peng Y, Xu H (2019) EZH2 upregulation by ERa induces proliferation and migration of papillary thyroid carcinoma. BMC. Cancer. 19(1), 1094. https://doi.org/10.1186/s12885-019-6306-9. 
Yin D, Zhu H, Hu P, Zhao Q (2008) Genotoxic effect of 2,4,6-trichlorophenol on P53 gene in zebrafish liver. Environ. Toxicol. Chem. 28(3), 603-608. https://doi.org/10.1897/08-317.1.

Yu LQ, Zhao GF, Feng M, Wen, W, Li K, Zhang PW, Peng X, Huo WJ, Zhou HD (2014) Chronic exposure to pentachlorophenol alters thyroid hormones and thyroid hormone pathway mRNAs in zebrafish. Environ. Toxicol. Chem. 33(1), 170-176. https://doi.org/10.1002/etc.2408.

Zhang Q, Jiang C, Li H, Zhang C, Wu H, Huang F (2020) Effect of the Interaction Between Cadmium Exposure and CLOCK Gene Polymorphisms on Thyroid Cancer: a Case-Control Study in China. Biol. Trace. Elem. Res. 196(1), 86-95. https://doi.org/10.1007/s12011-019-01904-2.

Zhang X, Zhang X, Niu Z, Qi Y, Huang D, Zhang Y (2014) 2,4,6-Trichlorophenol cytotoxicity involves oxidative stress, endoplasmic reticulum stress, and apoptosis. Int. J. Toxicol. 33(6), 532-541.

https://doi.org/10.1177/1091581814557701.

Zhang Y, Liu M, Liu J, Wang X, Wang C, Ai W, Chen S, Wang H (2018) Combined toxicity of triclosan, 2,4dichlorophenol and 2,4,6-trichlorophenol to zebrafish (Danio rerio). Environ. Toxicol. Pharmacol. 57, 9-18. https://doi.org/10.1016/j.etap.2017.11.006.

Zhang Y, Wei F, Zhang J, Hao L, Jiang J, Dang L, Mei D, Fan S, Yu Y, Jiang L (2017) Bisphenol A and estrogen induce proliferation of human thyroid tumor cells via an estrogen-receptor-dependent pathway. Arch. Biochem. Biophys. 633, 29-39. https://doi.org/10.1016/j.abb.2017.09.002.

Zheng RS, Sun KX, Zhang SW, Zeng HM, Zou XN, Chen R, Gu XY, Wei WW, He J (2019) Report of cancer epidemiology in China, 2015. Zhonghua. Zhong. Liu. Za. Zhi. 41(1), 19-28.

https://doi.org/10.3760/cma.j.issn.0253-3766.2019.01.005.

Zheng RZ, Zhang QH, He YX, Zhang Q, Yang LS, Zhang ZH, Zhang XJ, Hu JT, Huang F (2013) Historical Longterm Exposure to Pentachlorophenol Causing Risk of Cancer - A Community Study. Asian. Pac. J. Cancer. Prev. 14(2), 811-816. https://doi.org/10.7314/apjcp.2013.14.2.811.

Zheng W, Yu H, Wang X, Qu W (2012) Systematic review of pentachlorophenol occurrence in the environment and in humans in China: not a negligible health risk due to the re-emergence of schistosomiasis. Environ Int. 42, 105-16. https://doi.org/10.1016/j.envint.2011.04.014.

\section{Supplementary Material}

Fig. A.1. Association between 2,4-DCP, 2,4,6-TCP, PCP and the risk of thyroid cancer in male and female subgroups. The dose-response relationship between the concentrations of three chlorophenols after natural logarithmic conversion and the risk of thyroid cancer in different subgroups was investigated by using restricted cubic spline regression analysis. In the restricted cubic spline functions, three nodes were used, which were the 10th, 50th and 90th percentiles of each urine chlorophenol concentration. The odds ratios (solid red lines) and 95\% confidence intervals (shaded areas) were estimated using the 10th percentile of the natural logarithmic transformation for each concentration as a reference. The horizontal dotted line indicates that each reference value of odds ratio is 1.0. The bars represented histograms of urinary chlorophenols 
distribution among male and female participants. The model corrected for urinary iodine (continuous variable), BMI (continuous variable), household income (categorical variable), living conditions (categorical variable), drinking (categorical variable), family history of thyroid disease (categorical variable), and family history of malignancy (categorical variable).

Similarly, the same restricted cubic spline regression analysis was used to obtain the dose-response relationship between the natural logarithmic conversion concentrations of three chlorophenols and the risk of different types of thyroid cancer (see from Fig. A.2. Fig. A.5.)

Fig. A.2. Association between three chlorophenols and the risk of thyroid cancer with different diameters.

Fig. A.3. Association between three chlorophenols and the risk of thyroid cancer with different metastatic characteristics.

Fig. A.4. Association between three chlorophenols and the risk of unilateral and bilateral thyroid cancer.

Fig. A.5. Association between three chlorophenols and the risk of unifocal and multifocal thyroid cancer.

\section{Tables}

Table 1 Baseline characteristics and pathologic characteristics of study population 


\begin{tabular}{|c|c|c|c|}
\hline & $\begin{array}{l}\text { Case } \\
(\mathrm{N}=297)\end{array}$ & $\begin{array}{l}\text { Control } \\
(\mathrm{N}=297)\end{array}$ & $P$ \\
\hline Male Sex, n (\%) & 93(31.3) & $93(31.3)$ & - \\
\hline Age, years \pm SD & $46.2 \pm 12.5$ & $47.0 \pm 13.2$ & 0.452 \\
\hline $\mathrm{BMI}, \mathrm{kg} / \mathrm{m}^{2} \pm \mathrm{SD}$ & $24.3 \pm 3.10$ & $23.4 \pm 3.40$ & $<0.001$ \\
\hline $\mathrm{BMI}, \mathrm{kg} / \mathrm{m}^{2}, \mathrm{n}(\%)$ & & & 0.010 \\
\hline$<18.5$ & $6(2.0)$ & $15(5.1)$ & \\
\hline $18.5-$ & $138(46.5)$ & $165(55.6)$ & \\
\hline $24.0-$ & $120(40.4)$ & $88(29.6)$ & \\
\hline$>28.0$ & $33(11.1)$ & $29(9.8)$ & \\
\hline Education level & & & 0.129 \\
\hline Junior middle school or less & $174(58.6)$ & 192(64.6) & \\
\hline High school or above & $123(41.4)$ & 105(35.4) & \\
\hline Household income, yuan/year & & & 0.020 \\
\hline$£ 30000$ & $43(14.5)$ & $69(23.2)$ & \\
\hline $30001 \sim$ & 118(39.7) & 112(37.7) & \\
\hline${ }^{3} 60000$ & $136(45.8)$ & 116(39.1) & \\
\hline Living conditions & & & 0.004 \\
\hline Live together & 273(91.9) & $250(84.2)$ & \\
\hline Solitary & $24(9.1)$ & $47(15.8)$ & \\
\hline Smoking status & & & 0.099 \\
\hline Yes & $49(16.5)$ & $35(11.8)$ & \\
\hline No & $248(83.5)$ & $262(88.2)$ & \\
\hline Alcohol drinking & & & $<0.001$ \\
\hline Yes & $72(24.2)$ & $37(12.5)$ & \\
\hline No & $225(75.8)$ & $260(87.5)$ & \\
\hline Exercise, times / week & & & 0.318 \\
\hline$<1$ & 196(66.0) & $203(68.4)$ & \\
\hline $1 \sim$ & $53(17.8)$ & $40(13.5)$ & \\
\hline 35 & $48(16.2)$ & $54(18.1)$ & \\
\hline
\end{tabular}




\begin{tabular}{|c|c|c|c|}
\hline History of radiation exposure & & & 0.165 \\
\hline Yes & $225(75.8)$ & $210(70.7)$ & \\
\hline No & $72(24.2)$ & $87(29.3)$ & \\
\hline Family history of thyroid diseases & & & $<0.001$ \\
\hline Yes & $43(14.5)$ & $11(3.7)$ & \\
\hline No & $254(85.5)$ & $286(96.3)$ & \\
\hline Family history of malignant tumor & & & 0.005 \\
\hline Yes & $70(23.6)$ & $43(14.5)$ & \\
\hline No & $227(76.4)$ & $254(85.5)$ & \\
\hline \multicolumn{4}{|l|}{ Pathology } \\
\hline Papillary & $276(92.9)$ & - & \\
\hline follicular & $7(2.4)$ & - & \\
\hline Medullary & $8(2.7)$ & - & \\
\hline Poorly differentiated & $6(2.0)$ & - & \\
\hline \multicolumn{4}{|l|}{ Tumor Diameter, cm } \\
\hline$\leq 1.0$ & $111(37.4)$ & - & \\
\hline$>1.0$ & $170(57.2)$ & - & \\
\hline Not available & $16(5.4)$ & - & \\
\hline \multicolumn{4}{|l|}{ Unilateral or bilateral } \\
\hline Unilateral & 188(63.3) & - & \\
\hline Bilateral & $89(30.0)$ & - & \\
\hline Not available & $20(6.7)$ & - & \\
\hline \multicolumn{4}{|l|}{ Unifocal or multifocal } \\
\hline Unifocal & 168(56.6) & - & \\
\hline Multifocal & $104(35.0)$ & - & \\
\hline Not available & $25(8.4)$ & - & \\
\hline \multicolumn{4}{|l|}{ Metastasis } \\
\hline Yes & $143(48.1)$ & - & \\
\hline No & $147(49.5)$ & - & \\
\hline Not available & $7(2.4)$ & - & \\
\hline
\end{tabular}


Table 2 Concentrations of chlorophenols and biochemical indexes in thyroid cancer and control groups

\begin{tabular}{|c|c|c|c|c|c|c|}
\hline \multirow{2}{*}{$\begin{array}{l}\text { Object } \\
\text { Detections }\end{array}$} & \multirow[t]{2}{*}{ Unit } & \multicolumn{2}{|c|}{ Case $(n=297)$} & \multicolumn{2}{|c|}{ Control(n=297) } & \multirow{2}{*}{$\begin{array}{l}P \text { - } \\
\text { value }\end{array}$} \\
\hline & & Median & $\begin{array}{l}\text { 25th-75th } \\
\text { Percentile }\end{array}$ & Median & $\begin{array}{l}\text { 25th-75th } \\
\text { Percentile }\end{array}$ & \\
\hline $2,4-\mathrm{DCP}$ * & $\mu g / L$ & 0.68 & $0.35-1.17$ & 0.50 & $0.24-0.92$ & 0.001 \\
\hline 2,4,6-TCP & $\mu g / L$ & 0.36 & $0.17-0.59$ & 0.24 & $0.12-0.52$ & 0.001 \\
\hline PCP & $\mu g / L$ & 0.63 & $0.31-1.21$ & 0.41 & $0.13-0.81$ & $<0.001$ \\
\hline $2,4-\mathrm{DCP}$ a & $\mu \mathrm{g} / \mathrm{g}$ & 0.67 & $0.33-1.52$ & 0.51 & $0.21-1.10$ & 0.001 \\
\hline $2,4,6-\mathrm{TCP}^{\mathrm{a}}$ & $\mu g / g$ & 0.34 & $0.34-0.69$ & 0.26 & $0.13-0.51$ & 0.001 \\
\hline $\mathrm{PCP}{ }^{\mathrm{a}}$ & $\mu \mathrm{g} / \mathrm{g}$ & 0.62 & $0.62-1.28$ & 0.39 & $0.17-0.95$ & $<0.001$ \\
\hline lodine & $\mu g / L$ & 255.76 & 203.08-494.39 & 209.08 & $135.18-303.90$ & $<0.001$ \\
\hline lodine $^{a}$ & $\mu g / g$ & 297.78 & $176.80-524.44$ & 197.54 & $137.87-301.06$ & $<0.001$ \\
\hline Creatinine & $g / L$ & 1.01 & $0.57-1.54$ & 1.04 & $0.68-1.48$ & 0.512 \\
\hline FT3 & $\mathrm{pmol} / \mathrm{L}$ & 4.68 & $4.32-4.94$ & 4.68 & $4.28-5.20$ & 0.454 \\
\hline FT4 & $\mathrm{pmol} / \mathrm{L}$ & 16.25 & $14.70-16.88$ & 16.24 & $14.56-17.89$ & 0.286 \\
\hline TSH & $\mathrm{ulU} / \mathrm{mL}$ & 2.88 & $1.78-3.46$ & 2.65 & $1.66-3.62$ & 0.311 \\
\hline
\end{tabular}

*2,4-Dichlorophenol (2,4-DCP), 2,4,6-Trichlorophenol (2,4,6-TCP), Pentachlorophenol (PCP), Free Triiodothyronine (FT3), Free Thyroxine (FT4), Thyroid Stimulating Hormone (TSH)

a: Urinary concentration of chlorophenols and iodine had been corrected by creatinine

Table 3 The association between urinary chlorophenols exposure and thyroid cancer risk 


\begin{tabular}{|c|c|c|c|c|c|c|}
\hline Chlorophenols & Case & Control & Unadjusted OR $(95 \% \mathrm{Cl})$ & $\begin{array}{l}\mathrm{P}- \\
\text { trend }\end{array}$ & $\begin{array}{l}\text { Adjusted OR } \\
(95 \% \mathrm{Cl})^{a}\end{array}$ & P-trend \\
\hline \multicolumn{7}{|l|}{ 2,4-DCP * } \\
\hline$<0.21$ & 46 & 74 & 1 & 0.013 & 1 & 0.060 \\
\hline $0.21-$ & 73 & 74 & $1.70(0.98-2.99)$ & & $1.80(0.94-3.44)$ & \\
\hline $0.51-$ & 80 & 74 & $1.85(1.11-3.08)$ & & $1.82(1.02-3.24)$ & \\
\hline$\geq 1.11$ & 98 & 75 & $2.42(1.42-4.14)$ & & $2.28(1.24-4.18)$ & \\
\hline Continuous ${ }^{b}$ & 297 & 297 & $1.32(1.08-1.60)$ & 0.006 & $1.27(1.04-1.56)$ & 0.021 \\
\hline \multicolumn{7}{|l|}{ 2,4,6-TCP } \\
\hline$<0.13$ & 40 & 74 & 1 & 0.001 & 1 & 0.001 \\
\hline $0.13-$ & 65 & 74 & $1.62(0.98-2.65)$ & & $1.40(0.78-2.50)$ & \\
\hline $0.26-$ & 88 & 74 & $2.16(1.32-3.54)$ & & $2.52(1.39-4.54)$ & \\
\hline$\geq 0.51$ & 104 & 75 & $2.85(1.68-4.84)$ & & $3.09(1.66-5.77)$ & \\
\hline Continuous $^{b}$ & 297 & 297 & $1.40(1.06-1.84)$ & 0.016 & $1.52(1.12-2.08)$ & 0.008 \\
\hline \multicolumn{7}{|l|}{ PCP } \\
\hline$<0.18$ & 38 & 74 & 1 & $<0.001$ & 1 & 0.001 \\
\hline $0.18-$ & 60 & 74 & $1.82(1.05-3.18)$ & & $1.36(0.72-2.59)$ & \\
\hline $0.40-$ & 88 & 74 & $2.72(1.57-4.69)$ & & $2.46(1.30-4.64)$ & \\
\hline$\geq 0.95$ & 111 & 75 & $3.80(2.14-6.78)$ & & $3.30(1.71-6.36)$ & \\
\hline Continuous ${ }^{b}$ & 297 & 297 & $1.20(1.02-1.40)$ & 0.025 & $1.24(1.06-1.46)$ & 0.008 \\
\hline
\end{tabular}

* 2,4-Dichlorophenol (2,4-DCP), 2,4,6-Trichlorophenol (2,4,6-TCP), Pentachlorophenol (PCP), Odds ratio (OR), confidence interval $(\mathrm{Cl})$

a: Adjusted for BMI, household income level, living conditions, alcohol consumption, family history of thyroid disease, family history of malignant tumor and urinary iodine

b: Odds ratio calculated for each $1 \mathrm{ug} / \mathrm{g}$

Table 4 The relationship between three chlorophenols and the risk of thyroid cancer with different diameters 


\begin{tabular}{|c|c|c|c|c|c|c|c|c|c|c|}
\hline \multirow[t]{2}{*}{ Chlorophenols } & \multicolumn{5}{|c|}{$\begin{array}{l}\text { Microcarcinomas (Tumor Diameter } \leq 1 \\
\mathrm{~cm} \text { ) }\end{array}$} & \multicolumn{5}{|c|}{$\begin{array}{l}\text { Larger Tumor Size (Tumor Diameter }>1 \\
\mathrm{~cm} \text { ) }\end{array}$} \\
\hline & Case & Control & $\begin{array}{l}\mathrm{OR} \\
\mathrm{a}\end{array}$ & $\begin{array}{l}95 \% \mathrm{Cl} \\
\mathrm{a}\end{array}$ & $\begin{array}{l}\text { P- } \\
\text { value }\end{array}$ & Case & Control & $\begin{array}{l}\mathrm{OR} \\
\mathrm{a}\end{array}$ & $\begin{array}{l}95 \% \mathrm{Cl} \\
\mathrm{a}\end{array}$ & $\begin{array}{l}\mathrm{P}- \\
\text { value }\end{array}$ \\
\hline \multicolumn{11}{|l|}{$2,4-\mathrm{DCP}$ * } \\
\hline$<0.21$ & 14 & 25 & 1 & & 0.336 & 31 & 45 & 1 & & 0.702 \\
\hline $0.21-$ & 32 & 29 & 2.40 & $\begin{array}{l}(0.86- \\
6.60)\end{array}$ & & 36 & 39 & 1.36 & $\begin{array}{l}(0.52- \\
3.58)\end{array}$ & \\
\hline $0.51-$ & 36 & 29 & 2.19 & $\begin{array}{l}(0.86- \\
5.57)\end{array}$ & & 35 & 42 & 1.48 & $\begin{array}{l}(0.62- \\
3.50)\end{array}$ & \\
\hline$\geq 1.11$ & 29 & 28 & 1.88 & $\begin{array}{l}(0.71- \\
5.00)\end{array}$ & & 68 & 43 & 1.70 & $\begin{array}{l}(0.66- \\
4.30)\end{array}$ & \\
\hline Continuous ${ }^{b}$ & 111 & 111 & 1.26 & $\begin{array}{l}(0.82- \\
1.95)\end{array}$ & 0.283 & 170 & 170 & 1.24 & $\begin{array}{l}(0.92- \\
1.66)\end{array}$ & 0.148 \\
\hline \multicolumn{11}{|l|}{ 2,4,6-ТCP } \\
\hline$<0.13$ & 18 & 29 & 1 & & 0.422 & 21 & 42 & 1 & & 0.030 \\
\hline $0.13-$ & 29 & 31 & 1.24 & $\begin{array}{l}(0.50- \\
3.02)\end{array}$ & & 31 & 39 & 0.99 & $\begin{array}{l}(0.42- \\
2.32)\end{array}$ & \\
\hline $0.26-$ & 33 & 28 & 1.55 & $\begin{array}{l}(0.60- \\
3.98)\end{array}$ & & 50 & 41 & 2.74 & $\begin{array}{l}(1.16- \\
6.52)\end{array}$ & \\
\hline$\geq 0.51$ & 31 & 23 & 2.16 & $\begin{array}{l}(0.82- \\
5.74)\end{array}$ & & 58 & 48 & 2.58 & $\begin{array}{l}(1.01- \\
6.60)\end{array}$ & \\
\hline Continuous $^{b}$ & 111 & 111 & 1.82 & $\begin{array}{l}(0.92- \\
3.60)\end{array}$ & 0.084 & 170 & 170 & 1.68 & $\begin{array}{l}(1.10- \\
2.56)\end{array}$ & 0.016 \\
\hline \multicolumn{11}{|l|}{ PCP } \\
\hline$<0.18$ & 18 & 31 & 1 & & 0.344 & 19 & 40 & 1 & & 0.079 \\
\hline $0.18-$ & 31 & 24 & 1.78 & $\begin{array}{l}(0.65- \\
4.87)\end{array}$ & & 28 & 44 & 1.62 & $\begin{array}{l}(0.58- \\
4.44)\end{array}$ & \\
\hline $0.40-$ & 29 & 32 & 1.98 & $\begin{array}{l}(0.78- \\
5.00)\end{array}$ & & 49 & 36 & 2.86 & $\begin{array}{l}(1.02- \\
8.00)\end{array}$ & \\
\hline$\geq 0.95$ & 33 & 24 & 2.51 & $\begin{array}{l}(0.90- \\
6.95)\end{array}$ & & 74 & 50 & 3.24 & $\begin{array}{l}(1.20- \\
8.76)\end{array}$ & \\
\hline Continuous $^{b}$ & 111 & 111 & 1.18 & $\begin{array}{l}(0.86- \\
1.62)\end{array}$ & 0.294 & 170 & 170 & 1.24 & $\begin{array}{l}(1.02- \\
1.52)\end{array}$ & 0.034 \\
\hline
\end{tabular}

* 2,4-Dichlorophenol (2,4-DCP), 2,4,6-Trichlorophenol (2,4,6-TCP), Pentachlorophenol (PCP), Odds ratio (OR), confidence interval $(\mathrm{Cl})$ 
a: Adjusted for BMI, household income level, living conditions, alcohol consumption, family history of thyroid disease, family history of malignant tumor and urinary iodine

b: Odds ratio calculated for each $1 \mathrm{ug} / \mathrm{g}$

Table 5 The association between three chlorophenols and the risk of thyroid cancer with different metastatic characteristics 


\begin{tabular}{|c|c|c|c|c|c|c|c|c|c|c|}
\hline \multirow[t]{2}{*}{ Chlorophenols } & \multicolumn{5}{|c|}{ Non-metastatic Thyroid Carcinoma } & \multicolumn{5}{|c|}{ Metastatic Thyroid Carcinoma } \\
\hline & Case & Control & $\begin{array}{l}\mathrm{OR} \\
\mathrm{a}\end{array}$ & $\begin{array}{l}95 \% \mathrm{Cl} \\
\mathrm{a}\end{array}$ & $\begin{array}{l}\mathrm{P}- \\
\text { value }\end{array}$ & Case & Control & $\begin{array}{l}\mathrm{OR} \\
\mathrm{a}\end{array}$ & $\begin{array}{l}95 \% \mathrm{Cl} \\
\mathrm{a}\end{array}$ & $\begin{array}{l}\mathrm{P} \text { - } \\
\text { value }\end{array}$ \\
\hline \multicolumn{11}{|l|}{$2,4-D C P$ * } \\
\hline$<0.21$ & 28 & 34 & 1 & & 0.276 & 18 & 38 & 1 & & 0.009 \\
\hline $0.21-$ & 46 & 43 & 1.46 & $\begin{array}{l}(0.61- \\
3.49)\end{array}$ & & 27 & 28 & 1.40 & $\begin{array}{l}(0.50- \\
3.95)\end{array}$ & \\
\hline $0.51-$ & 48 & 35 & 1.92 & $\begin{array}{l}(0.85- \\
4.31)\end{array}$ & & 32 & 38 & 1.42 & $\begin{array}{l}(0.58- \\
3.52)\end{array}$ & \\
\hline$\geq 1.11$ & 25 & 35 & 0.95 & $\begin{array}{l}(0.35- \\
2.56)\end{array}$ & & 66 & 39 & 4.06 & $\begin{array}{l}(1.68- \\
9.81)\end{array}$ & \\
\hline Continuous $^{b}$ & 147 & 147 & 1.03 & $\begin{array}{l}(0.74- \\
1.44)\end{array}$ & 0.864 & 143 & 143 & 1.80 & $\begin{array}{l}(1.25- \\
2.60)\end{array}$ & 0.002 \\
\hline \multicolumn{11}{|l|}{ 2,4,6-TCP } \\
\hline$<0.13$ & 25 & 30 & 1 & & 0.310 & 14 & 41 & 1 & & 0.001 \\
\hline $0.13-$ & 39 & 42 & 0.92 & $\begin{array}{l}(0.41- \\
2.08)\end{array}$ & & 23 & 32 & 2.12 & $\begin{array}{l}(0.84- \\
5.38)\end{array}$ & \\
\hline $0.26-$ & 46 & 44 & 1.46 & $\begin{array}{l}(0.64- \\
3.34)\end{array}$ & & 39 & 30 & 3.96 & $\begin{array}{l}(1.53- \\
10.24)\end{array}$ & \\
\hline$\geq 0.51$ & 37 & 31 & 1.89 & $\begin{array}{l}(0.78- \\
4.62)\end{array}$ & & 67 & 40 & 7.78 & $\begin{array}{l}(2.78- \\
21.74)\end{array}$ & \\
\hline Continuous $^{b}$ & 147 & 147 & 1.55 & $\begin{array}{l}(0.87- \\
2.76)\end{array}$ & 0.137 & 143 & 143 & 1.87 & $\begin{array}{l}(1.24- \\
2.84)\end{array}$ & 0.003 \\
\hline \multicolumn{11}{|l|}{ PCP } \\
\hline$<0.18$ & 14 & 31 & 1 & & 0.035 & 22 & 41 & 1 & & 0.001 \\
\hline $0.18-$ & 33 & 35 & 2.26 & $\begin{array}{l}(0.82- \\
6.22)\end{array}$ & & 24 & 39 & 0.80 & $\begin{array}{l}(0.30- \\
2.12)\end{array}$ & \\
\hline $0.40-$ & 53 & 46 & 2.98 & $\begin{array}{l}(1.12- \\
7.87)\end{array}$ & & 33 & 25 & 3.15 & $\begin{array}{l}(1.18- \\
8.40)\end{array}$ & \\
\hline$\geq 0.95$ & 47 & 35 & 5.11 & $\begin{array}{l}(1.67- \\
15.60)\end{array}$ & & 64 & 38 & 4.27 & $\begin{array}{l}(1.68- \\
10.86)\end{array}$ & \\
\hline Continuous $^{b}$ & 147 & 147 & 1.37 & $\begin{array}{l}(0.98- \\
1.91)\end{array}$ & 0.060 & 143 & 143 & 1.26 & $\begin{array}{l}(1.04- \\
1.53)\end{array}$ & 0.019 \\
\hline
\end{tabular}

*2,4-Dichlorophenol (2,4-DCP), 2,4,6-Trichlorophenol (2,4,6-TCP), Pentachlorophenol (PCP), Odds ratio (OR), confidence interval $(\mathrm{Cl})$

a: Adjusted for BMI, household income level, living conditions, alcohol consumption, family history of thyroid disease, family history of malignant tumor and urinary iodine 


\section{Figures}
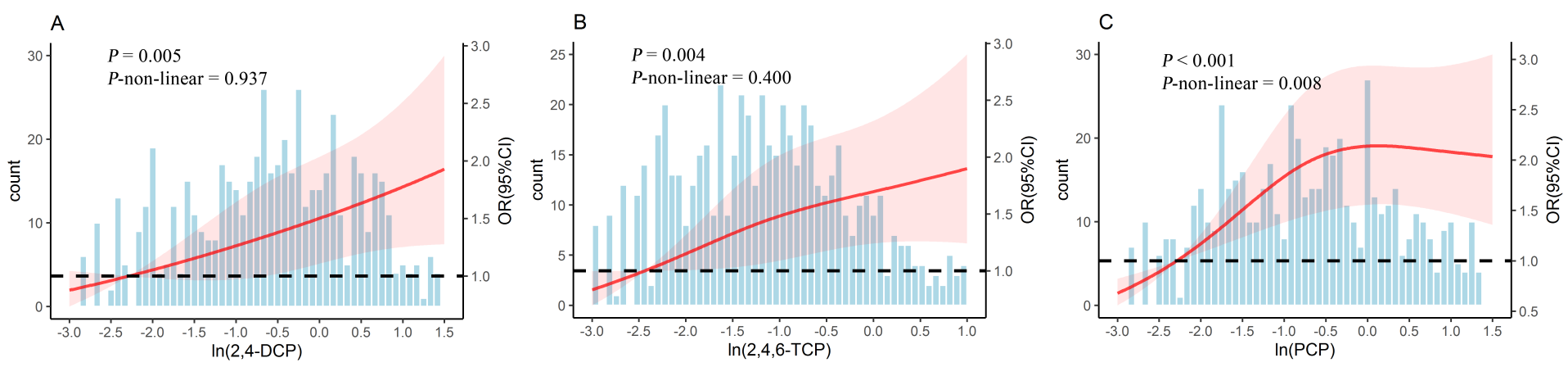

Figure 1

Adjusted restricted cubic splines for the relationship between In-transformed creatinine adjusted urinary chlorophenols and the risk of thyroid cancer. Association between the three chlorophenols and the risk of thyroid cancer. In the restricted cubic spline analysis, three nodes were used, which were the 10th, 50th and 90th percentiles of each urine chlorophenol concentration. The odds ratios (solid red lines) and 95\% confidence intervals (shaded areas) were estimated using the 10th percentile of the natural logarithmic transformation for each concentration as a reference. The horizontal dotted line indicates that each reference value of odds ratio is 1.0. The bars represented histograms of urinary chlorophenols distribution among included participants. The model corrected for urinary iodine (continuous variable), BMI (continuous variable), household income (categorical variable), living conditions (categorical variable), drinking (categorical variable), family history of thyroid disease (categorical variable), and family history of malignancy (categorical variable). (A) The restricted cubic spline for the association between In-transformed urinary 2,4DCP and the risk of thyroid cancer. (B) The restricted cubic spline for the association between In-transformed urinary 2,4,6-TCP and the risk of thyroid cancer. (C) The restricted cubic spline for the association between Intransformed urinary PCP and the risk of thyroid cancer.

\section{Supplementary Files}

This is a list of supplementary files associated with this preprint. Click to download.

- Fig.A.1.tif

- Fig.A.2.tif

- Fig.A.3.tif

- Fig.A.4.tif

- Fig.A.5.tif

- TableA.1.docx

- TableA.2.docx 
- TableA.3.docx

Page 26/26 